\title{
Innovative and Creative Entrepreneurship Support Services at Universities
}

\author{
Mónica Arroyo-Vázquez* \\ Peter van der Sijde** \\ Fernando Jiménez-Sáez ${ }^{* * *}$ \\ *Instituto IDEAS - Universidad Politécnica de Valencia; \\ Camino de Vera, s/n. E-46022, Valencia, Spain \\ ** Vrije Universiteit Amsterdam \\ Faculty of Social Sciences \\ ${ }^{* * *}$ INGENIO (CSIC-UPV) \\ Camino de Vera, s/n. E-46022, Valencia, Spain \\ Corresponding address: moarroyo@ideas.upv.es; phone: +34-963877726; fax: +34-963877722; \\ http://www.ideas.upv.es
}

\begin{abstract}
In the context of the Entrepreneurial Universities, new stakeholders and new roles for the old ones have emerged. Accordingly, university entrepreneurship support services have to behave in a creative and innovating manner in order to actively support business creation at the university. This means that a common framework is necessary that includes the different stakeholders and goals, which gives a clear picture of the entrepreneurship encouragement and business development support (EE\&BDS) process. We show a model for knowledge transfer and companies' growth within the context of entrepreneurial universities. This alternative integrating approach of the different stakeholders, actors, activities, tools, goals and needs, help us to arrange and manage them in a better way. Our analysis allows us to show the role and relationships among the different university stakeholders and how this integrating approach contributes to enhance the EE\&BDS process for this institution.
\end{abstract}

Keywords: Innovative services, entrepreneurial university, entrepreneurship education, business development support 


\section{Introduction}

In the present society the role of universities is not just restricted to teaching and research activities (Etzkowitz 1998). Even more, it demands a major involvement of universities in the economic and social development process. This has resulted in the rise of a new type of university: the entrepreneurial university, which combines and integrates the traditional activities of teaching and research with the contribution to the economic and social development (Etzkowitz 1998; Goddard 1998). Therefore, an entrepreneurial university, in order to attend successfully to the society's demands (and be recognised as such), must behave according to this new role. In this context, one of the aims of the entrepreneurial universities is the entrepreneurship encouragement and the business development support (EE\&BDS) process. The Entrepreneurship Support Services (ESS), are those units responsible for the promotion of this process at universities. These services must practice what they preach becoming themselves innovative and creative in order to be able to actually support the promotion of innovative businesses. This attitude however need from the involvement of new stakeholders and the consideration of new roles for the old ones. This means on the one hand the need to put their specific objectives into connection and on the other, to relate them to the whole university goal within an entrepreneurial context. To make this possible, it is necessary to develop a systemic framework (Clark, 1996; Etzkowitz, 2003) that incorporates the different stakeholders and their goals, to have a clear picture of the EE\&BDS process at universities. In this sense, we have to take into account that, as public service, there is a great number of stakeholders involved. It is especially difficult to detect needs, objectives and performance of this agents (Armistead and Pettigrew, 2008).

In this paper we present the model for the EE\&BDS process in entrepreneurial universities (Arroyo-Vázquez and Van der Sijde 2008), as a new tool for the promotion of innovative ESS. This model shows arrangements of stakeholders and actors in such a way that allows the optimization of the EE\&BDS process (e.g. Van der Sijde 2002). The proposal model focuses in four key areas that these services will need to foster in order to support the creation of innovative business: (1) entrepreneurship culture, (2) entrepreneurship support, (3) new business launch support and (4) business growth support. The model helps us to clearly identify a mechanism and the optimal timing to satisfy entrepreneurs and business needs thanks to the promotion of innovative and creative ESS.

This paper shows how to implement a theoretical model within an innovative ESS based on both the Polytechnic University of Valencia's IDEAS Institute experience and the case of University of Twente (Van der Sijde and Van Alste 1998) other successful cases. The interaction of the EE\&BDS model with successful experiences and cooperation formulas among different agents will provide us the foundations to build an innovative ESS. Finally some outcomes and conclusions are drawn.

\section{The framework and context}

The university contribution to society is an old issue that nowadays again receives attention from researchers and policymakers. In this respect the entrepreneurial university idea (first identified by Davies, 1987) is recognised as a powerful concept to frame this contribution in clear opposition to the classical university concept and social contribution. According to the new role assigned to them we find a common and widely accepted belief: the higher the amount of spin-off companies a university is able to create, the "more entrepreneurial" this university will be considered. In this respect we agree with Clark (2004) when he asserts that "entrepreneurialism in universities should not be seen 
as synonymous with commercialization". Additionally, the study of the most successful entrepreneurial universities in the world has resulted in a wide literature production related to their characteristics as well as the way how they can successfully turn into one of them: although most are based on $n=1$ analyses. We find several studies dealing with these issues such as O'Shea et al. (2007); Clark (1998, 2004); Etzkowitz (1983, 2004) among others. According to these authors, the entrepreneurial university can be understood as a flexible organization that interacts with its social and economical environment adapting itself to the changes and looks for additional sources of funds for research, teaching, technology transfer, commercialisation, etc. Entrepreneurial universities have in common a strengthened steering core, an expanded developmental periphery, a stimulated academic heartland, a diversified funding base and an integrated entrepreneurial culture as Clark (1998) describes but without formulating the dependency between these five characteristics.

The entrepreneurial university, as defined above, must attend to a wide number of activities related to its three basic roles as it is stated in the university third mission literature (Molas-Gallart et al, 2002): teaching, research and socio-economic development contribution ("outreach"), and at the same time, they have to be managed jointly. All these activities as well as their respective management must be carried out in an entrepreneurial way. This, in the end, means that a large variety of stakeholders are involved.

The entrepreneurial culture is defined by Gibb (1999) as the "sets of values, beliefs and attitudes commonly shared in a society which underpin the notion of an entrepreneurial 'way of life' as being desirable and in turn support the pursuit of 'effective' entrepreneurial behaviour by individuals or groups". According with this, we recognise two critical tasks related to the entrepreneurial culture closely linked to those carried out at innovative ESS. The first one is the Entrepreneurship Encouragement defined as the "dynamisation" (Castro et al, 2001) (and entrepreneurial culture building process) among the involved stakeholders (always including entrepreneurs) as well as the promotion of research and teaching activities in entrepreneurship and related fields. In this definition we want to point out that "dynamisation" is understood as the induced behavioural change that "moves someone to do something" (Castro et al, 2001). According to these authors two activities must be promoted in the "dynamisation" process: awareness and motivation activities on the one hand and the provision of facilities on the other. The second critical task is the Business Development Support. We define it as the process that encompasses the opportunity search and recognition, opportunity development, business start-up and business development and growth. We argue that these two tasks must be developed jointly, within an integrating framework since many stakeholders are involved in both and the different activities of each task can benefit from a synergic stream among them improving therefore the whole EE\&BDS process. Hence, the systemic consideration of the EE\&BDS process reinforces all its elements and provides the optimal framework to obtain optimal outcomes through the building of stakeholders' networks.

There is a large amount of literature produced around the EE\&BDS at universities, but most of it tackles the issue separately, not as a whole process or in its wide sense. For instance, entrepreneurship encouragement is usually considered just as the promotion of knowledge transfer from universities through the creation of spin-off companies. On the other hand, the Business Development Support process at universities is just considered when is related to the spin-off companies in which universities have Intellectual Property Rights (IPR) or shares on the spin-off. Some authors consider this process to start with IP protection and ending in IP valorisation via shareholder agreements with the spin-off (e.g. Cuyvers and Zimmermann, 2002). However and in opposition to these views, Dalmau et al. (2003) considers the EE\&BDS process at universities as a whole in which several activities must be developed in relation to each other to promote new business from students, graduates and university's staff. This model is built around five phases: awareness, "Opportunity Cell building", pre-incubation, incubation and exploitation. It takes into account not only the opportunity recognition, the opportunity development and 
the opportunity exploitation, but also the awareness process previous to the opportunity identification. However this model does not consider the EE\&BDS process in a way where external and internal university stakeholders are involved and work using networks to develop it. Additionally, the building process of entrepreneurial culture is just referred to as the entrepreneurs' awareness activities, but it does not involve other stakeholders or activities. An alternative view that we must take into account is Nikos' Entrepreneurship in Network model (Nikos, 2004) which considers the development of its activities in the entrepreneurship domain in four main activities: research, teaching, business development support and training and consultancy. We believe that this model offers a broader view since it takes into account additional activities to that of spin-off creation and also several stakeholders and networks for their development. A different approach is offered by Rasmussen and Borch (2006) through the development of dynamic capabilities within the university: new paths; the past, present and future balance; the resources reconfiguration and integration and the creation of new knowledge resources. Once again attention is placed on the creation of research-based spin-off ventures, but these authors consider that stakeholders from within and outside the university are involved in the spin-off creation process who have partly conflicting objectives. We also need to consider that ESS approach differs from the rest of the university services so here the Universities have to face the challenge of how to coordinate each other in order to avoid predictable tensions (Rasmussen et al. 2006).

\section{Towards an Innovative ESS}

\section{The model}

The starting point, as we have already mentioned is the EE\&BDS model at entrepreneurial universities to build an innovative and creative ESS. We have to take into account that services at entrepreneurial universities must evolve to adapt themselves to changes and users' needs even more if the user is an entrepreneur and the service is address towards the promotion of entrepreneurial culture supporting innovative business. The next figure depicts the EE\&BDS process. We use this scheme to show the key point for the implementation of an innovative and creative ESS at universities. First, we analyse the whole model paying speciual attention to the implications of a holistic consideration. Afterwards we will show how to implement all the needed services in each section in order to be innovative and creative.

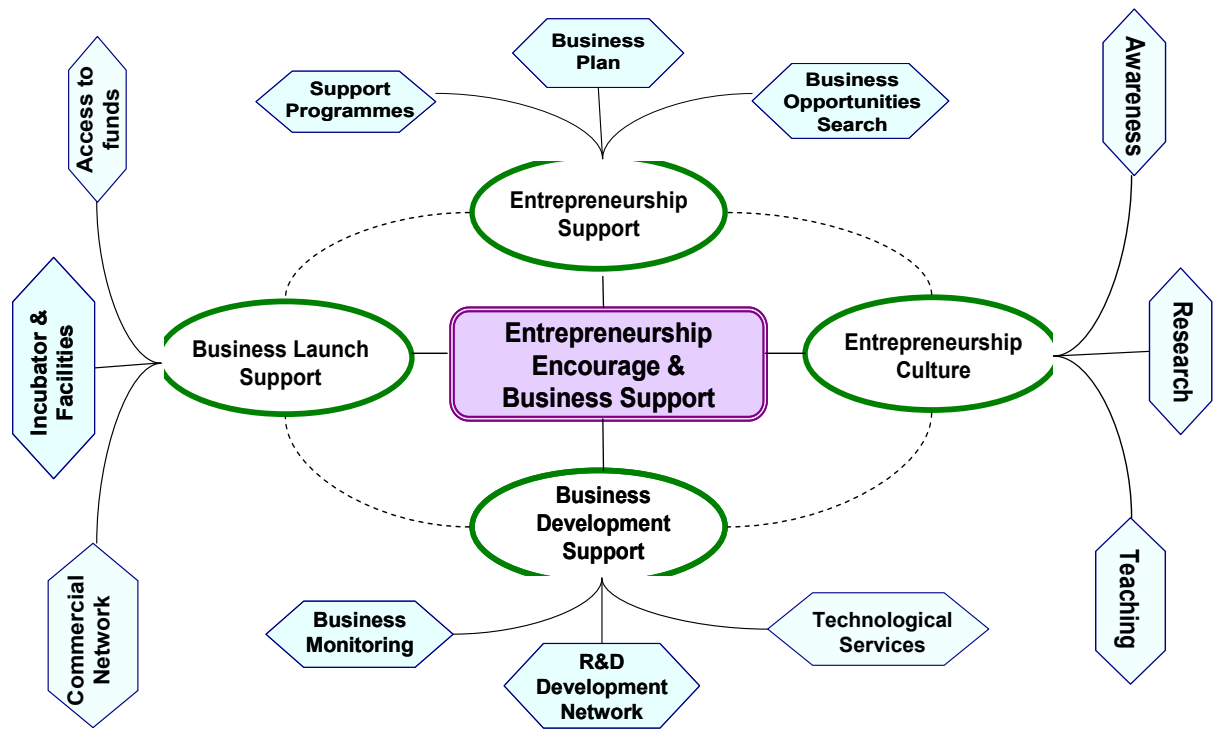

Figure 1: Illustration of the EE\&BDS model (Arroyo-Vázquez and Van der Sijde 2008) 


\section{Creativity and innovation to manage an integrating model}

As we mentioned before, the ESS is the university unit in charge of the EE\&BDS process implementation. In many cases the tasks that we have described with this model are carried out by many different services depending on different responsible university structures even external to the university. If we add to this picture opposing interests that many times exhibit the involved personnel at those services then, the right management of this model toward a common end is difficult to imagine. Hence it seems to be necessary a tool that ease the strategic design of the collaboration among the different agents and personnel involved in such a way that we are able to reach the objectives both at an individual and collective levels. According to Kirwan et al. (1996) the entrepreneurial process take place in social systems, where four mechanisms (Groen, 2005) are embedded, related to the specific capitals needed. These capitals (see Table 1) are defined as strategic capital, economic capital, cultural capital and social network capital. We argue that entrepreneurs and business' needs along the EE\&BDS process can be grouped into these four capitals, but we also need to add an additional category: hosting and facilities, since we consider that incubation and other facilities are crucial for the process success. The satisfaction of these needs will ease the business development and growth in the earlier years. However it is not essential to consider this new category in the first model's stage, Entrepreneurship Culture, since the activities here carried out are not related to hosting.

Table 1: Capitals, scope and resources. Source: adapted from Groen, 2005

\begin{tabular}{|c|l|l|}
\hline Capitals needed & \multicolumn{1}{|c|}{ Scope } & \multicolumn{1}{c|}{ Resource } \\
\hline Strategic Capital (SC) & $\begin{array}{l}\text { Definition and attainment } \\
\text { of strategic goals }\end{array}$ & $\begin{array}{l}\text { Power, authority, influence, } \\
\text { strategic intent }\end{array}$ \\
\hline Economic Capital (EC) & Economic optimization & Money and funds \\
\hline Cultural Capital (CC) & $\begin{array}{l}\text { Pattern maintenance and } \\
\text { institutionalization of } \\
\text { shared symbols }\end{array}$ & $\begin{array}{l}\text { Values, organization, knowledge, } \\
\text { skills, experience, technology }\end{array}$ \\
\hline $\begin{array}{l}\text { Social Network Capital } \\
\text { (NC) }\end{array}$ & Interactions between actors & $\begin{array}{l}\text { Contacts (multiplex, filling } \\
\text { structural holes, cohesive, } \\
\text { equivalent) }\end{array}$ \\
\hline Host and Facilities (HF) & $\begin{array}{l}\text { Location and physical } \\
\text { identity }\end{array}$ & \begin{tabular}{l} 
Place and facilities \\
\hline
\end{tabular}
\end{tabular}

In addition, we must consider the stakeholders taking part in each stage of this process. Table 2 shows a list of stakeholders that may take part at any stage in the process. We do not make any distinction among them regarding their membership to the university of out the university. According to each specific case, these stakeholders will belong to the university or will belong to external organization to the university. We want to stress the need to consider all of them in the process. 
Table 2: Possible stakeholders considered in the EE\&BDS process

\begin{tabular}{|l|rl|}
\hline \multicolumn{2}{|c|}{ Stakeholders to be considered } \\
\hline - University Managers & - & Consultancies (both external and \\
- Business Creation Support Service & & internal to the University) \\
- Technology Transfer Office & - & Business \& Associations \\
- Incubator Centre and Facilities & - & Technology Institutes \\
- Research Institutes and Centres & - & Seed Capital Networks \\
- Departments & - & Financial Entities \\
- Faculties & - & Government (European, National, \\
- University Employment Service & & Regional, Local levels) \\
\hline
\end{tabular}

In order to analyse what the stakeholder's contribution should be, we take into account the previous groups of topics (Table 1) in each stage of our EE\&BDS process. Therefore we have to analyse the contribution of each stakeholder in each capital at each stage. Note that all the capital requirements are covered only if the contributions of all the stakeholders (both external and internal) are taken into account. We can represent those contributions by means of the following table (Table 3), where we can identify who (stakeholder) participates in what (model stage) and how (what capital provides).

Table 3: Stakeholders' contribution in the EE\&BDS process

\begin{tabular}{|l|l|l|l|l|l|l|l|l|l|l|l|l|l|l|l|l|l|l|l|}
\hline & \multicolumn{3}{c|}{$\begin{array}{c}\text { Entrepreneurship } \\
\text { Culture }\end{array}$} & \multicolumn{3}{c|}{$\begin{array}{c}\text { Entrepreneurship } \\
\text { Support }\end{array}$} & \multicolumn{3}{c|}{$\begin{array}{c}\text { Business Launch } \\
\text { Support }\end{array}$} & \multicolumn{3}{c|}{$\begin{array}{c}\text { Business Develop } \\
\text { Support }\end{array}$} \\
\hline STAKEHOLDERS & SC & EC & CC & NC & SC & EC & CC & NC & HF & SC & EC & CC & NC & HF & SC & EC & CC & NC & HF \\
\hline University Managers & & & & & & & & & & & & & & & & & & & \\
\hline $\begin{array}{l}\text { Business Creation } \\
\text { Support }\end{array}$ & & & & & & & & & & & & & & & & & & & \\
\hline $\begin{array}{l}\text { Technology Transfer } \\
\text { Office }\end{array}$ & & & & & & & & & & & & & & & & & & & \\
\hline Incubator Center & & & & & & & & & & & & & & & & & & & \\
\hline Research Institutes & & & & & & & & & & & & & & & & & & & \\
\hline Departments & & & & & & & & & & & & & & & & & & & \\
\hline Faculties & & & & & & & & & & & & & & & & & & & \\
\hline $\begin{array}{l}\text { Employment } \\
\text { Services }\end{array}$ \\
\hline $\begin{array}{l}\text { External } \\
\text { Consultancy }\end{array}$
\end{tabular}

This table is a new helpful tool for the service design as well as for the design of a collaboration strategy among the involved agents.

Many different formulas have been used so far to manage ESS (independent foundations with or without university shareholding, external managers, university service, etc). However we hold that the organisation structure is not as important as the way the service 
is managed. An integrated model requires an integrating management but also (and more importantly) a long term macro-perspective that also considers all those daily activities. Only an entrepreneurial university, as Clark (2004) defines it will be able to implement the ESS with the capacity to yield optimal results and will benefit in the end to the territory in the form of economic and social development. This means that the university must promote the entrepreneurship culture from a wide point of view making it a milestone for all the services. Therefore the support to an innovating business idea will become a habit and will reinforce the links between the university and those entrepreneurs that at any point in time looked for the university ESS support. This behaviour reinforces the social consideration of the university and its active role within the territory.

This long term approach works under a service management logic reflected in the following figure.

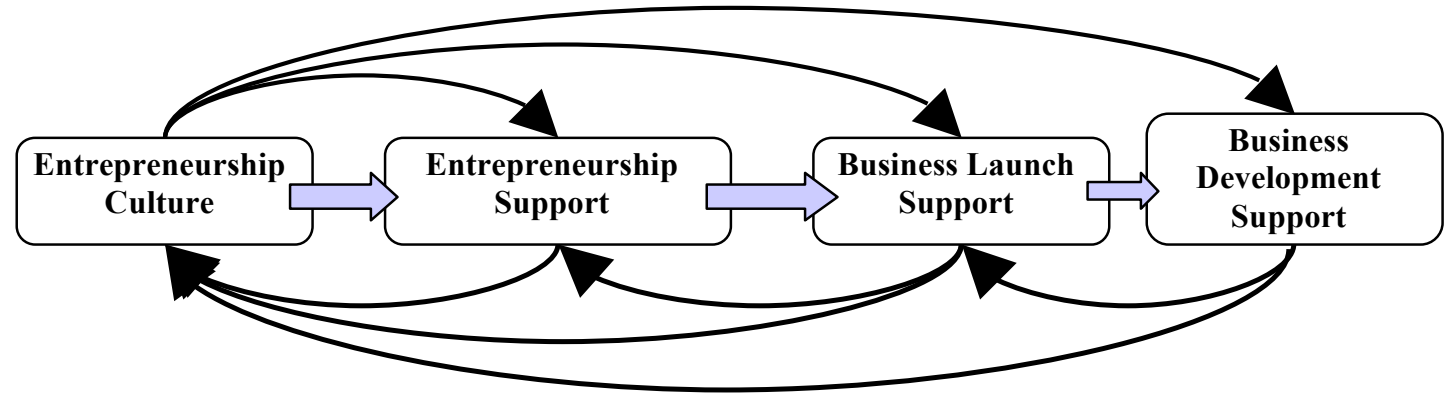

Figure 2: EE\&BDS model's logic

As we can see, each activity is linked to the whole process. Therefore, they will offer and receive feedback from the rest of the stages and activities, which in the end means that the optimal model's logic rests on an accurate Entrepreneurship Culture encouragement. This stage's success is a necessary but not sufficient condition for the whole model's success. In this figure we illustrate how this stage influences and is influenced by the rest of the model's elements. We must take this into account if we want to design and offer ideal services.

As magic formulas do not exist in the management of these types of services some key considerations have to be taken into account if we want to succeed. They will be presented and described as long as we deal with each model stage. However, we have to keep in mind that the university characteristics, timing and environment are key factors to obtain ideal results.

\section{Entrepreneurship Culture}

We consider that entrepreneurial behaviour among stakeholders and entrepreneurs must be encouraged to achieve optimal results of the ESS. Many times entrepreneurship encouragement is understood as a marketing activity in order to attract entrepreneurs to create new businesses. However this behaviour does not yield optimal results. We claim that Entrepreneurship Culture defined as the creation of a culture around entrepreneurship is not just limited to the "entrepreneurial culture" (Gibb, 1999). It also integrates research and teaching activities related to entrepreneurship and connected issues. We show in the Figure 3 the key activities that we consider necessary to create an Entrepreneurship Culture climate as well as the objectives that we must take into account in each one. 


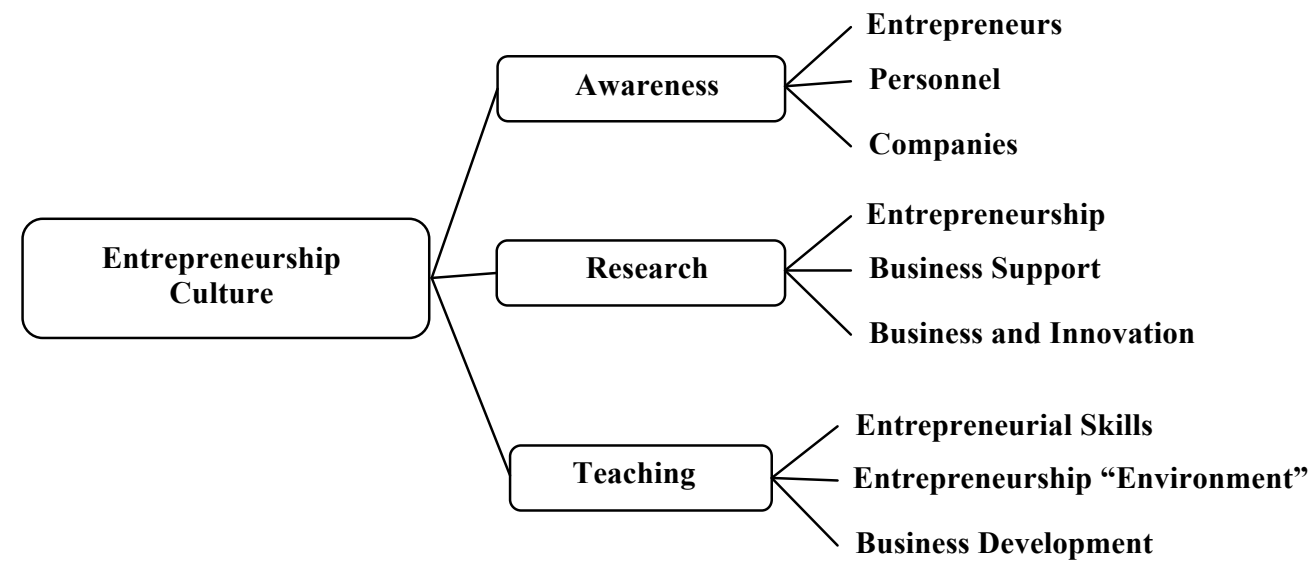

Figure 3: Activities and objectives to build the Entrepreneurship Culture

The construction of this area rests on the promotion of awareness, research and teaching activities. With respect to awareness, the target groups are entrepreneurs, academic and professional personnel at universities and companies. Regarding entrepreneurs, the goal is to inform them about the process and its possibilities, as well as to show them new business creation as a self-employment possibility. Personnel attitude and creativity are key for these sorts of activities. An innovating ESS is continuously considering new proactive awareness forms moving in the direction of entrepreneurs. On the other hand, ESS also needs to be proactive with both the university management staff and regional and /or local governments. It is also ESS's mission to aware policy makers about the need to foster entrepreneurship culture.

The second target group, personnel, might include staff, researcher, lecturers and any other person or institution involved as stakeholder in the process. The goal of the awareness activities addressed to this group is the creation and promotion of a proactive behaviour towards entrepreneurship support. For instance, researchers should be proactive and help entrepreneurs to understand technological issues or advise them about the R\&D implementation in the future for the firm. Companies are also a target group of awareness activities. In this case, the goal is to promote the implementation of an entrepreneurial culture in the companies as well as the creation of a proactive attitude toward the cooperation in the entrepreneurship support. In this sense, according to Grant et al. (1996), we have to make companies aware of the activities of universities and, therefore, about the possibility to collaborate with universities and what they can expect from such collaboration.

With regard to research activities they will be developed in respect to entrepreneurship in a broad sense, what allows us to have a wider knowledge on skills, entrepreneurs' behaviour and the reasons why they decide to create a new business, among others. Another research field that we consider in this area is business support structures. The goal of this sort of research is to find new mechanisms, activities, tools, etc. to support entrepreneurship and business development. Finally, we also propose research on business and innovation.

Teaching activities must be carried out both at undergraduate and post-graduate levels. The goal of this activity is not just to train entrepreneurs in business creation (entrepreneurs skills teaching), but also to train people that may support and advise entrepreneurs (entrepreneurship environment teaching) and enterprises (business development teaching) within the EE\&BDS process and its services. 


\section{Entrepreneurship Support}

This area integrates the activities that must be carried out to offer entrepreneurs support through the process of business plan development, when the entrepreneur has not created the new business yet. We consider that this stage must contemplate the business opportunity search, since it is necessary, on the one hand, to know about the different sectors' trends in order to offer a better advisement to the entrepreneurs and, on the other, to build a research results "observatory" to detect on time those results that are capable of future commercialisation and analyse whether a new spin-off will be the optimal mechanism to do so.

Business plan development is a very hard and time consuming activity that entrepreneurs must carry out by themselves as a (training) activity to prepare to their future business, among other reasons. This activity involves a lot of issues referred to the new business: strategy, management, accounting, fiscal liabilities, and marketing, among others. Many of them are usually completely new for entrepreneurs. Therefore, mentoring is crucial in this stage to guide them into this long path. Once the business plan is completed, an assessment is required to determine whether it is viable to create the new business. In many cases the answer to this question appears during the business development process and are the entrepreneurs who realize themselves if the business will or will not be feasible and viable.

We consider that different support programmes must be offered to attend different types of entrepreneurs and business ideas (self-employment, high-tech business, to exploit research results, etc.), since different needs have to be covered in each case. Specific training activities (different and with other goals to the teaching activities) addressed to entrepreneurs and businessmen, are necessary to complement this training period. Finally, we have to take into account that entrepreneurs have to have access to financial resources during this stage. Seed capital, banks, etc. usually do not provide financial support during the business plan development. Therefore, if we want encourage the new business creation some financial support must be offered. All the activities and objectives to be covered during this stage are depicted in the Figure 4.

Once again the key point to how to offer the services instead of the number of them and the amount of information. These services must be adapted to the entrepreneurs' needs. This means service flexibility in many aspects (time schedule, resources, creativity to solve entrepreneurs' problems, capacity to offer networking). This means that these services must be offered by personnel with entrepreneurial characteristics in order to really help other entrepreneurs.

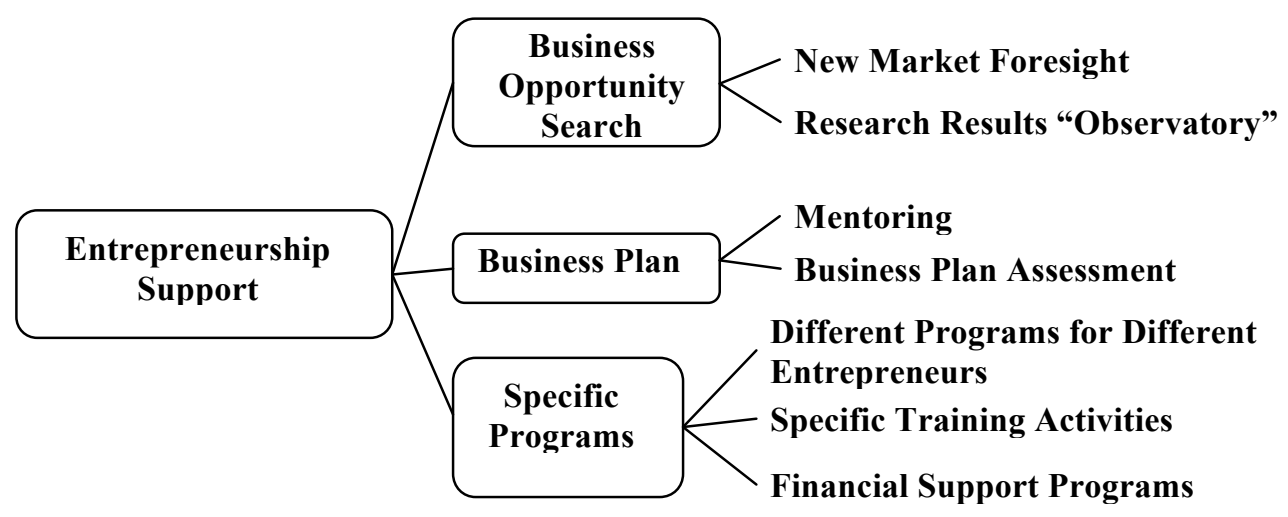

Figure 4: Activities and objectives to support entrepreneurship 


\section{Business Launch Support}

This stage embraces the support activities to the new businesses during the start-up process. Many university ESS consider that its tasks end after the business is created. However all this effort is in many cases useless if there is not a monitoring process during the first business steps. An entrepreneurial university must get involved along the whole process including these first steps in the real business world.

It departs from the legal arrangements and search of funds for the new businesses' set up to their introduction in the market and initial commercialization process. We also want to consider within this stage the hosting and search of relationships with partners, customers and suppliers. We consider that this stage usually lasts no less than one year but no more than three. The Figure 5 illustrates these activities.

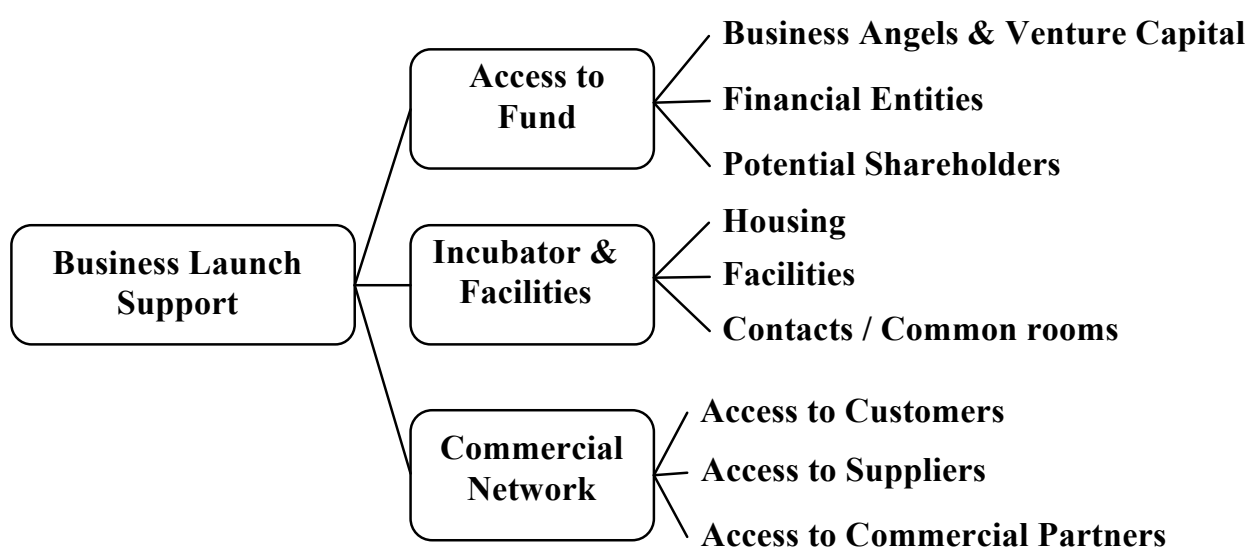

Figure 5: Activities and support to the Business Launch

\section{Business Development Support}

We consider that entrepreneurial universities must support not only the new businesses' creation and start-up processes, but also they should maintain and feed a fluent relationship with these new firms offering them further support and services during the business firms' development and growth stage. Therefore we propose the business monitoring activity during the company's early years as well as further support address to ease growth if the company might require.

During this stage the company has to come into contact with several partners to develop R\&D activities. The building process of this sort of networks is not an easy task and the company will need support from the university and other stakeholders. Furthermore, in this stage, the company needs technological and advanced services support in order to grow and develop R\&D activities. According to our model proposal the activities carried out during this stage help both the company and the university to establish strong ties. The Figure 6 depicts the activities carried out during this final stage. The model's optimal operation foresees the participation of entrepreneurs and stakeholders in each stage helping and contributing to the company's growth. This, in the end results in strong ties among firms and the university and related stakeholders that help close the cycle and create a cooperation climate enhancing therefore the social contribution of the entrepreneurial university. 


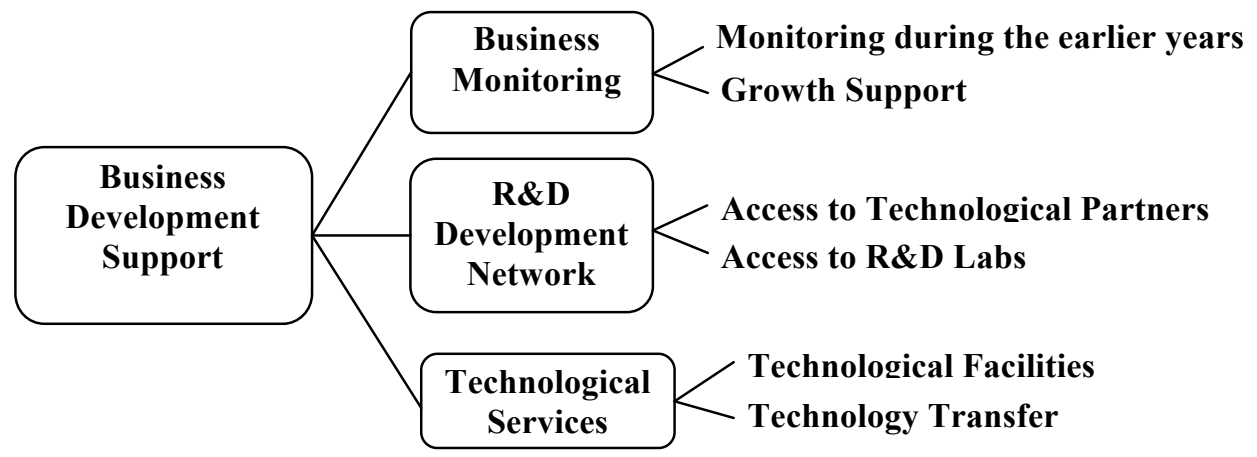

Figure 6: Activities for Business Development Support

We have illustrated in this section the different activities and goals to implement an innovating ESS. However we need to take into account that the specific tools in each activity must be developed according to the characteristics of each university. Therefore some activities and/or goals can be changed or re-oriented. However we think that the four main areas (Entrepreneurship Culture, Entrepreneurship Support, Business Launch Support and Business Development Support) must be contemplated in an ESS in order to keep the systemic and integrating approach contributing therefore to produce and receive the optimal synergic outcomes from the model. However, in the short run, we can obtain some outcomes (even good ones) if we just carry out some of the four main activities proposed in our EE\&BDS model. But we argue that it is necessary to develop the four areas, attending to the general goals described in each one in order to obtain the optimal outcomes in the long run.

\section{Outcomes and Conclusions}

To be an innovating ESS means much more than supporting new business creation. Encouragement of an entrepreneurial culture and the consequent behaviour among their stakeholders and actors is behind this services' role. In this context, the EE\&BDS process, is crucial to implement innovating ESS at universities, and has to involve the different stakeholders, actors, activities and tools, by getting them together into a common framework. Therefore, it is necessary an integrating and systemic approach of this process that take into account all these elements.

We showed the need of a sort of management that considers and integrating mode of our model and takes into account both long term and day by day in the management. Furthermore we stress the need of the management adaptation to the entrepreneurs' needs using creativity and innovation as key elements for the success.

We have presented an ESS based on the EE\&BDS model that contemplates a wide entrepreneurial process that integrates entrepreneurship culture, entrepreneurship support, new business launch support and business growth support. We have emphasised the Entrepreneurship Culture as a crucial stage to the optimal model's logic.

The achievement of the optimal outcomes from the model is directly linked to its integrating and systematic consideration: only the actual involvement of all the stakeholders and the creation of networks among them to carry out the activities will satisfy the entrepreneurs, business and own model's needs accurately. Therefore, the consideration of an integrated and systemic approach to the model is as a helpful tool to enhance the ESS at universities. 


\section{References}

Armistead, C and Pettigrew, P. (2008) "Partnerships in the provision of services by multiagencies: four dimensions of service leadership and service quality". Service Business vol. 2 (1) pp. $17-32$

Arroyo-Vázquez, M; Van der Sijde, P.C. (2008) "Entrepreneurship encouragement and business development support at universities and science parks". Industry and Higuer Education, vol. 22 (1) pp. $37-48$

Castro, E.; Fernández de Lucio, I.; Gutiérrez, A. and Añón, M.J. (2001) "La Dinamización en la cooperación Investigación-Empresa: desarrollo conceptual y aplicaciones”. Mexico D.F.: ALTEC'2001 proceedings.

Clark, B. (1998) Creating Entrepreneurial Universities: Organizational Pathways of Transformation. Oxford: Pergamon Press.

Clark, B. (1996) “Creando Universidades Emprendedoras en Europa”. Revista Valenciana d'Estudis Autonomics, vol. 21, pp. 373-392.

Clark, B. (2004) "Delineating the Character of the Entrepreneurial University". Higher Education Policy, vol. 17, pp. 355-370.

Cuyvers, R. and Zimmermann, E. (2002) "KUL as a virtual incubator for new, knowledgeintensive busi-nesses", in K. Debackere and R. De Bondt (eds.) Leuven Research and Development: 30 years of break-throughs and innovations towards an entrepreneurial university. Leuven: KUL Press.

Dalmau, J.I.; Alonso, J.L. and Colomer, J. (2003). Programa IDEAS. Un modelo de éxito para fomentar la creación de empresas desde las universidades. Valencia: Universidad Politécnica de Valencia.

Davies, J.I. (1987) "The Entrepreneurial and adaptative university: characteristics of its organization and operation". International Journal of Institutional Management in Higher Education, vol.2, (1).

Etzkowitz, H. (1983) "Entrepreneurial scientists and entrepreneurial universities in American academic science”. Minerva, vol. 1 (2-3), pp. 198-233.

Etzkowitz, H. (1998) "The norms of entrepreneurial science: cognitive effects of the new university-industry linkages”. Research Policy, vol. 27 (8), pp.823-833.

Etzkowitz, H. (2003) 'Research groups as 'quasifirms' the invention of the entrepreneurial university”. Research Policy, vol. 32 (1), pp. 109-131.

Etzkowitz, H. (2004) "The evolution of entrepreneurial university". International Journal of Technology and Globalisation, vol. 1 (1), pp. 64-77.

Gibb, A. (1999) “Creating an entrepreneurial culture in support of SMEs”. Small Enterprise Development, vol. 10 (4), pp. 27-38.

Goddard, J. (1998) "The role of universities in regional development”. Working paper for CREColumbus. UNESCO: Paris.

Grant, C.A.; Van der Sijde, P.C.; Henry, C.; Koswenska, I.; Scott, t. and Chassagne, G. (1996)

"Routes of technology transfer to SMEs: a cross-european perspective". Industry \& Higher Education. Pp. 293-299.

Groen, A. (2005). "Knowledge intensive entrepreneurship in networks: towards a multi-level/multi dimensional approach". Journal of Enterprising Culture, vol.13 (1), pp.69-88. 
Kirwan, P; Van der Sijde, P. and Groen, A. (2006) "Assessing the needs of new technology based firms (NTBFs): an investigation among spin-off companies from six European Universities". The International Entrepreneurship and Management Journal, vol. 2 (2) pp. 173-187.

Molas-Gallart, J.; Salter, A.; Patel, P.; et al (2002) “Measuring third stream activities”. Internal report. Brighton, SPRU.

Nikos (2004) Progress Report 2001-2004. Nikos, University of Twente. The Netherlands. http://www.utwente.nl/nikos/news/progressreport.pdf.

O’Shea, R.P.; Allen, T.J.; Morse, K.P.; O’Gorman, C. and Roche, F. (2007) “Delineating the anatomy of an entrepreneurial university: the Massachusetts Institute of Technology experience". R\&D Management, vol. 37 (1), pp. 1-16.

Rasmussen, E. and Borch, O.J. (2006) "The university and the spin-off process. A dynamic capability approach", in David Urbano (Ed.) Diversity in entrepreneurship. 3rd Inter-RENT Online Publication. Turku: European Council for Small Business and Entrepreneurship.

Van der Sijde, P.C.; Ridder, A.; Van Benthem, J. and Groen, A. (2002) "Entrepreneurship and entrepreneurship stimulation at the University of Twente", in P.C. Van der Sijde, A. Ridder, J.M. Gòmez, J.T. Pastor, D. Galiano and I. Mira (eds.) Infrastructures for Academic Spin-off Companies, CEE Limencop, S.L.

Van der Sijde, P.C. and Van Alsté, J.A. (1998) "Support for entrepreneurship at the University of Twente". Industry \& Higher Education, vol.12 (December 1998) pp.367-372. 